\title{
TATB/KEL-F - PBX ANALYSIS
}

\author{
C. L. Schafber
}

DEVELOPMENT DIVISION

JULY - SEPTEMBER 1976

For

Normal Process Development

Endeavor No. 106

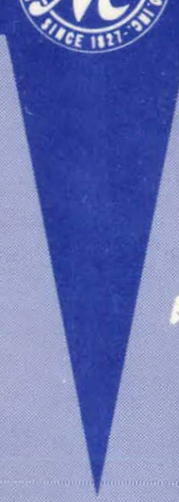

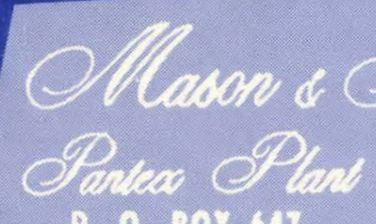

P. $0.00 x .07$

Acanilo, teras 79177

c0s-335-15a1

operated for the

ENERGY RESEARCH AND OEVELOPNENT ADMNISTRATION inder:

4. 5. GOVEAMKENT Contract BA IT MBAMC 487A 


\section{DISCLAIMER}

This report was prepared as an account of work sponsored by an agency of the United States Government. Neither the United States Government nor any agency Thereof, nor any of their employees, makes any warranty, express or implied, or assumes any legal liability or responsibility for the accuracy, completeness, or usefulness of any information, apparatus, product, or process disclosed, or represents that its use would not infringe privately owned rights. Reference herein to any specific commercial product, process, or service by trade name, trademark, manufacturer, or otherwise does not necessarily constitute or imply its endorsement, recommendation, or favoring by the United States Government or any agency thereof. The views and opinions of authors expressed herein do not necessarily state or reflect those of the United States Government or any agency thereof. 


\section{DISCLAIMER}

Portions of this document may be illegible in electronic image products. Images are produced from the best available original document. 


\section{NOTICE}

This report was prepared as an account of work sponsored by the United States Government. Neither the United States nor the United States Energy Research and Development Administration, nor their employees, nor any of their contractors, subcontractors, or their employees, makes any warranty, express or implied, or assumes any legal liability or responsibility for the accuracy, completeness or usefulness of any information, apparatus, product or process disclosed, or represents that its use would not infringe privately-owned rights. 


\title{
TATB/KEL-F - PBX ANALYSIS
}

\author{
C. L. Schafjer
}

DEVELOPMENT DIVISION

$\stackrel{i x}{?}$

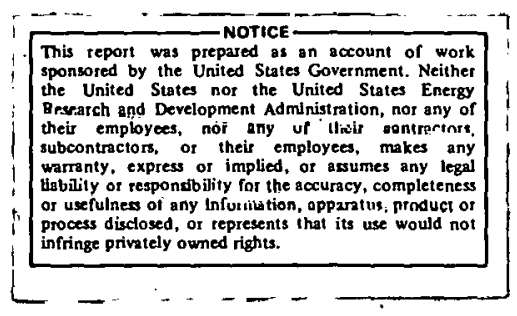

July - September 1976

Endeavor No. 106

EB

DISTRIBUTION OF THIS DOCUMENT IS UNLIMITED 


\section{DISCUSSION}

The analysis of RX-03-BB is complicated by the characteristics of triaminotrinitrobenzene (TATB). Some of these characteristics are: TATB is insoluble in most organic solvents; solvents for the Kel-F are also solvents for the impurities in the TATB; the various particle sizes of the TATB and the TATB coated by the Kel-F are difficult to extract from the Kel-F. Three methods have been used to obtain the analysis. These are reported as the methyl isobutyl ketone (MIBK), the nitric acid and the sulfuric acid methods. This report discusses, the analytical methods evaluated for RX-03-BB by Mason \& Hanger and the advantages and disadvantages of each method.

\section{ANALYSIS BY MIBK METHOD}

In each of four $150 \mathrm{~m}$ l beakers, 2 grams of RX-03-BB sample were weighed. The weight of each sample and its beaker were recorded. Sixty m $\ell$ of MIBK were added to each beaker. The beakers were warmed to approximately $80 \mathrm{C}$. Using a glass rod the samples were stirred until all $\mathrm{Kel-F}$ was dissolved in the MIBK. Each of the four medium fritted filters which had previously been cleaned were dried and weighed and the weights recorded. The samples from beakers were filtered using the prepared filters and were then washed with $25 \mathrm{ml}$ of new MIBK. Vacuum was applied to the filters using filtering flasks until the samples were air dried. Both filters and beakers were dried in a $100 \mathrm{C}$ vacuum oven for 2 hours. They were then removed from the oven and placed in a desiccator to cool to ambient temperature; then each beaker and filter. was weighed to determine weight loss of each sample. From these weights the percentage of Kel-F in each sample was determined. TATB from the sample trapped in the filter was cleaned using sulfuric acid.

\section{ANALYSIS BY SULFURIC ACID METHOD}

In each of four 9-dram bottles, 2-gram samples of RX-03-BB were weighed. The weight of each sample was recorded. Into each bottle 12 grams of 3 $\mathrm{mm}$ glass beads were weighed and recorded.

Twenty me of $98 \%$ sulfuric acid was added. Each bottle was sealed using a Teflon-lined cap and placed on wrist action shaker adapted so that each bottle moves back and forward approximately $4 \mathrm{~cm}$. The bottles were shaken until all TATB had been dissolved from the Kel-F which required approximately 4 to 6 hours. Using new sulfuric acid each sample was washed into a precleaned and weighed coarse fritted filter. The bottle and filters were rinsed until sulfuric acid was no longer yellow in color. Vacuum was applied to the filters until acid coated only the glass beads. The acid was removed from the filtering flasks and the bottles were washed with distilled water until all the sample and glass beads had been transferred into filters. Vacuum was then applied to the filter until the sample was air dried. The filters were placed in a $100 \mathrm{C}$ vacuum oven, dried four hours and placed in a desiccator 
to cool to ambient temperature. Each filter was weighed and the weight of Kel-F determined in each sample by subtraction. Percentage of Kel-F was determined in each sample from the weights. The filters were cleaned using MIBK. This method is the same as reported by LASL and adapted to Pantex equipment.

\section{ANALYSIS BY NITRIC ACID METHOD}

In each of four $250 \mathrm{~m} \&$ flasks, 2-gram samples of RX-03-BB were weighed. The weights of sample and flask were recorded. One hundred $m l$ of $70 \% \mathrm{HNO}_{3}$ were added to each flask, which was fitted with a condenser. Using a hot plate the $\mathrm{HNO}_{3}$ was refluxed for four hours. A precleaned and dried 60 me medium fritted filter was weighed for each sample. The Kel-F that remained in the flasks was filtered. Each flask was rinsed with $60 \mathrm{C}$ nitric acid $(25 \mathrm{ml})$, then washed through the filters. Each flask was washed with 25 me of distilled water and then filtered. The flasks and filters were dried in a $100 \mathrm{C}$ vacuum oven for approximately four hours. They were then placed in a desiccator to conl to ambient temperature. The flasks and filters were weighed and the Kel-F percentage determined.

\section{REPORTED ANALYSIS}

A control batch of RX-03-BB was formulated to give 93.50\% TATB. The analysis of this batch is reported in Table I as the control sample.

Analyses by the three methods are reported for six different Pantex lots of RX-03-BB in Table I. The analys is of TATB only and Kel-F only were also performed by the three different methods and are reported in Table II. All analyses in Tables I and II are reported with a 95\% confident level.

\section{COMPARISON OF THE THREE METHODS}

The MIBK method of analysis was found the easiest to perform but had more chance for error. The impurities in the TATB dissolved by the MIBK caused the Kel-F percentage to be high. Some TATB particles were so small that they pass through the filters and also plugged the filters, preventing further filtration. Cleanup of filters with sulfuric acid for reuse was also a problem.

The nitric acid method has two disadvantages. TATB that is completely covered by Kel-F is difficult to remove by nitric acid, and the nitric acid trapped in the Kel-F during reflux is difficult to remove during washing and drying.

The sulfuric acid method requires more time and is more sensitive to analyst errors if care and good laboratory techniques are not followed. The sample must be shaken until all the TATB is dissolved, and the sulfuric acid must be removed from the filters before drying. 
Table I. RX-03-BB Analysis

\section{RX-03-BB}

Sample

Blend No. 11

Blend No. 10

Blend No. 7

Blend No. 12

Blend No. 13

Blend No. 14

Control Sample
$\mathrm{H}_{4} \mathrm{SO}$

Method

\% TATB
MIBK

Method

$\%$ TATB
$\mathrm{HNO}_{3}$

Method

$\%$ TATB

$92.16 \pm 0.09 \quad 90.75 \pm 0.28 \quad 92.26 \pm 0.09$

$92.23 \pm 0.06$

$92.25 \pm 0.45$

$92.52 \pm 0.06$

$92.25 \pm 0.50$

$92.43 \pm 0.28$

$92.40 \pm 0.11$

$91.87 \pm 0.20$

$91.51 \pm 0.20$

$91.82 \pm 0.18$

$92.10 \pm 0.35$

$91.76 \pm 0.24$

$91.76 \pm 0.46$

$92.14 \pm 0.14$

$92.16 \pm 0.07$

$92.10 \div 0.14$

$93.42 \pm 0.14$

$92.69 \pm 0.09$

$93.35 \pm 0.53$

Table II. Analysis of TATB Only and Kel-F Only

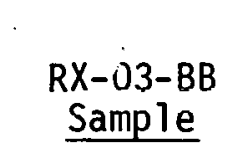

TATB

$\mathrm{Kel}-\mathrm{F}$

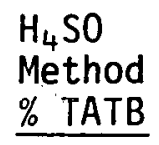

$99.95 \pm 0.14$

$99.94 \pm 0.06$
MIBK

Method

\% TATB

$99.44 \pm 0.16$

$99.69 \pm 0.63$
$\mathrm{HNO}_{3}$ Method

$\%$ TATB 


\section{CONCLUSIONS}

Based on approximately fifty different analyses using the sulfuric acid method by various laboratory analysts it has been found that the precision for these analyses as a group are less than the precision of the analyses by the nitric acid method. Even though the precision for the nitric acid run on the Kel-F shown in Table II is not desirable, this does not affect the accuracy of a PBX analysis to a large degree because the Kel$F$ is a small percentage of the total sample.

It is the opinion of the writer that the most accurate analysis can be performed on RX-03-BB by the sulfuric acid method when the same analyst using good laboratory procedures performs the analysis.

By using different analysts from day-to-day on many samples, the nitric acid method gives fast acceptable results with a good precision and less individual losses than the other two reported methods.

It is also concluded future analyses of $R X-03-B B$ may be subject to errors due to different TATB characteristics from other producers which have different impurities that can affect the analysis. 